\title{
The liver and anaesthesia
}

Lco Strunin MD FFARCS FRCP(C), J.M. Davies MSC MD FRCP(C)

\section{CONTENTS}

\author{
The liver and anaesthesia \\ Introduction \\ Normal anatomy and physiology \\ Pathophysiology \\ Biochemical derangements in liver disease \\ Viral hepatitis \\ Preoperative assessment \\ Anaesthetic considerations \\ Chronic liver disease \\ Biliary obstruction \\ Liver trauma and tumours \\ Postoperative liver dysfunction \\ References and further reading
}

This review of anaesthesia and the liver will concentrate on the common problems encountered daily by the anaesthetist. After brief summaries of normal anatomy and physiology, pathophysiology and preoperative assessment, the main emphasis will be on the practical anaesthetic considerations for patients with various forms of liver disease.

\section{Normal anatomy and physiology}

The liver is the largest single organ and is concerned through its storage, synthetic and excretory functions with nearly all the fundamental processes of the body. The liver contains only two types of cells, the hepatocyte and the Kupffer cell, but has a complex vascular supply and excretory system. Histological examination of the liver in man reveals a lobular structure with central veins. The portal vein, hepatic artery and bile duct have an intricate pattern of branching, such that, at each division they are bound together in a fibre sheath to form the portal tract. This ends as a network of sinusoids which connects the terminal branches of the hepatic venous and portal systems together. The total unit is usually described as a lobule or acinus.

The liver's excretory functions occur in two ways, by secretion of bile and directly into the hepatic veins. The biliary cannuliculi begin at the level of the hepatocytes and form the biliary tract which empties into the duodenum. The liver secretes about one litre of bile per day, which is produced continuously, but is only released into the duodenum during digestion. Normally, bile is stored in the gall bladder where it is concentrated to about one-fifth of its volume. Bile is made up of electrolytes, proteins, some carbohydrate, bilirubin, bile salts and lipids (cholesterol, phospholipids, and fatty acids). The cholesterol and fatty acids are held in solution by the detergent action of the bile salts and phospholipids, forming soluble molecular aggregates called micelles. The main function of bile salts is the emulsification of dietary fat, an essential part of fat absorption. In addition, the absorption of fat soluble vitamins, in particular, vitamins $A$ and $K$, is related to bile salts.

The liver's central role in carbohydrate, protein and fat metabolism is well recognised. Albumin is a major synthetic product and free fatty acids (FFA) generated by the liver provide $80-90$ per cent of normal body energy consumption. Drug, cholesterol, and steroid metabolism, both oxidative and reductive, is carried out within the hepatocytes. Water soluble metabolites are excreted into the plasma and bile. The liver is also a major storage site for such substances as vitamin $B_{12}$, jron, copper, and glycogen.

\section{Liver blood flow ${ }^{1,2}$}

The splanchnic organs are the gastrointestinal tract, spleen, pancreas, gallbladder, omentum and liver. The blood flowing through these organs is called the splanchnic blood flow (SBF). All the splanchnic organs have an arterial blood supply; their venous drainage, with the exception of the liver, passes into

From the Department of Anaesthesia, University of Calgary.

Adidress correspondence to: Dr. L.S. Strunin, Department of Anaesthesia, Foothills Hospital, 1403, 29th Street N.W., Calgary, Alberta, T2N 2 T9. 
the portal vein. Blood supply to the liver is in two parts: 70 per cent from the portal vein and 30 per cent from the hepatic artery, totalling some 25 per cent of resting cardiac output. However, the hepatic artery provides half of the liver's oxygen supply and thus, at rest, the organ is equally dependent on the portal vein and hepatic artery. Oxygen consumption is about $1 \mathrm{ml}$ per gram of liver tissue per minute. Blood drains from the liver via the hepatic veins directly into the inferior vena cava which passes through the posterior aspect of the liver substance.

Since all the blood flow of the splanchnic organs (SBF) may be accounted for by the flow in the portal vein and hepatic artery, measurement of hepatic blood flow (HBF) is more usual than measurement of $\mathrm{SBF}$; indeed, $\mathrm{HBF}$ and $\mathrm{SBF}$ are considered as interchangeable terms. In addition, liver blood flow (LBF) is commonly quoted as an alternative to $\mathrm{HBF}$ and again, these terms are considered interchangeable.

In man, non-invasive direct measurement of hepatic blood flow cannot be carried out. Therefore, estimated hepatic blood flow (EHBF) is calculated using the Fick principle. Indicators used include bromsulphthalein (BSP) and indocyanine green (ICG) ${ }^{3}$ Both BSP and ICG rely on good hepatocyte function for their uptake from the plasma and may not be satisfactory for measurement of EHBF in the presence of liver disease. In these circumstances, Kupffer cell function may still be normal and these cells will take up colloidal particles. If these are labelled with a radioactive marker such as Iodine $^{131}$, HBF may still be estimated. More recently, techniques using labelled compounds (e.g., Xenon, Technetium or Krypton) have been adopted. However, these methods are invasive as the indicator is normally injected into the splanchnic blood system, although the measurement is made extemally with a gamma camera over the liver.

Liver blood flow is affected by a number of factors during anaesthesia and surgery. These include: intermittent positive pressure ventilation, blood gas changes (in particular, $\mathrm{pCO}_{2}$ ), sympa thetic nervous system activity, splanchnic reflexes, changes in cardiac output, gastrointestinal and hepatic disease, direct effects of anaesthetic and other drugs used during anaesthesia, and surgical trauma. This latter may be the most important factor, particularly during abdominal surgery. In general, all anaesthetic agents and techniques, including spinal and epidural, lead to a fall in liver blood flow. The mechanism varies and includes: fall in cardiac output due to myocardial depression, increased splanchnic vascular resistance due to catecholamine stimulation and, in the case of spinal and epidural anaesthesia, a decrease in mean arterial blood pressure.

In patients with normal liver function, the fall in liver blood flow, as a result of anaesthesia and surgery, has, until recently, been assumed to have no detrimental effects. By contrast, in patients with pre-existing liver disease, it seems sensible to try to limit major decreases in liver blood flow. To this end, maintenance of a normal arterial $\mathrm{pCO}_{2}$ and avoidance of myocardial depression and hypotension seem obvious. In addition, recent experimental work on reductive metabolism of volatile anaesthetics such as halothane poses the question that even minor falls in liver blood flow may cause relative hypoxia of some liver cells and set the stage for postoperative liver damage (see below). It should be emphasized that, at present, these are theoretical considerations and have yet to be proven.

\section{Pathophysiology}

\section{Biochemical derangements in liver disease}

In liver disease, certain physiological functions may be particularly disturbed. Glucose homeostasis may be severely deranged, ${ }^{5}$ manifesting as hypoglycaemia, as a result of fasting or alcohol ingestion. Hypoglycaemia may occur in both the pre- and peroperative periods. Lactic acidosis, of two types (A and B), may be distinguished. Type A occurs when there is poor tissue perfusion, for example, following cardiac arrest or in patients with septic or endotoxic shock. Type B is not associated initially with evidence of poor tissue perfusion and occurs in patients with such diseases as diabetes, hepatic and renal dysfunction, septicaemia (without obvious shock) and leukaemia. ${ }^{6}$ In addition, the oral hypoglycaemic agent phenformin may precipitate type B acidosis in diabetic patients, particularly those who have concomitant cardiovascular and renal disease. Fructose, sorbitol and diethyl alcohol, if infused or ingested rapidly, may also give rise to type B lactic acidosis. Although the type $B$ syndrome is relatively rare, its mortality is high ( $50-70$ per cent).

Further disturbances in liver disease include 
TABLE I Serological diagnosis of etiology of vital hepatitis

\begin{tabular}{ll}
\hline Virus & Test \\
\hline A & Anti-HA \\
IgM antibody (acute infection) & HBs Ag \\
& surface or Australia antigen \\
& previous or present infection \\
& Hb c Ab \\
& core antibody \\
& active or recent infection \\
& Hb s $_{c}$ Ag \\
& "e" antigen \\
CMV & correlates with infectivity \\
EBV & CMV complement fixation \\
Herpes simplex & 'Mono-spot' screen \\
NANB & Serum titres; electron microscopy; culture \\
\hline
\end{tabular}

depression of protein synthesis and metabolism. This is evident from the low serum albumin and raised globulin concentrations, characteristic of chronic liver disease. Globulin, produced by the reticulo-endothelial system, is elevated, partially due to the response of the latter system to liver disease. In addition, clotting factors, such as prothrombin, factors IV, V, VII, and IX, are also depressed. In patients with decompensated (defined below) liver disease, any protein load, e.g., dietary or as a result of gastrointestinal haemorrhage, may lead to porto-systemic encephalopathy. The patient may become comatose with a fluctuating level of consciousness. The exact cause of hepatic coma is unknown, but is thought to relate to "coma factors," produced during protein metabolism which are nor-

TABLE II Categories of patients at risk for viral B carrier states $^{26}$

\begin{tabular}{|c|c|}
\hline Risk & \% of those with $H B S A G$ \\
\hline \multicolumn{2}{|l|}{ Low } \\
\hline Healthy adults & 0.3 \\
\hline \multicolumn{2}{|l|}{ Medium } \\
\hline $\begin{array}{l}\text { Health care workers } \\
\text { frequent exposure to blood }\end{array}$ & $1-2$ \\
\hline Male prisoners & $1-8$ \\
\hline \multicolumn{2}{|l|}{ High } \\
\hline Male homosexuals & 6 \\
\hline IV drug abusers & 7 \\
\hline Household contacts of HBV carriers & 3-6 \\
\hline Patients on hemodialysis & $3-10$ \\
\hline $\begin{array}{l}\text { Travellers/Immigrants from } \\
\text { regions of high HBV eademnicity }\end{array}$ & 13 \\
\hline
\end{tabular}

mally degraded by the liver, but in liver disease, spill over into the systemic circulation and enter the brain.

Steatorhoea and deficiency of fat soluble vitamins may accur. Of these, vitamin $\mathrm{K}$ is the most important clinically and is associated with reduced prothrombin activity. Accumulation of fat, leading to "fatty liver," may complicate diabetes, pregnancy, malnutrition and Cushing's syndrome. Drugs and chemicals such as corticosteroids, alcohol and carbon tetrachloride may also produce fat deposition in the liver. Reye's syndrome, a condition which occurs mainly in children, is also associated with massive fat deposition in the liver and other viscera.

\section{Viral hepatitis}

Viral hepatitis is most commonly caused by virus $A$ or virus B. Other viruses which may cause hepatitis include: non-A,non-B (NANB); cytomegalo-virus (CMV); Herpes simplex; and the Epstein-Barr virus (EB) of infectious mononucleosis. Of these, A, $C M V$, Herpes simplex and $E B$ virus cause an acute hepatitis which may range from mild infection to fulminant hepatic failure, but chronic liver disease is not a sequelae in patients who survive the infection and they are normally only infectious to others during the acute stage of their illness. In contrast, vinus B and NANB, as well as causing acute hepatitis, may also lead to chronic liver disease, carcinoma of the liver (hepatoma) and a chronic carrier state. Transfusion hepatitis was most commonly due to hepatitis B or CMV but, since the advent of serological testing, NANB is now the primary cause of this disease. ${ }^{7}$ The diagnosis of viral hepatitis from any cause is made on the clinical history and serological testing (Table I).

Patients with viral hepatitis pose two problems for the anaesthetist. Firstly, if there is any question that the patient may have acute viral hepatitis, all currently available evidence suggests that such patients should not, except in a dire emergency, undergo anaesthesia and surgery. It seems that there is often severe deterioration in liver function postoperatively, leading to fulminant hepatic failure. ${ }^{8}$ Secondly and more commonly, patients who may be at risk for being carriers of either hepatitis $B$ or NANB or those who have entered a chronic stage of their viral infection (Table 11 ), may require an 
TABLE II Physical findings in liver disease

(1) Central nervous system mental derangement (encephalopathy) varying from milo confusion to deep coma

(2) Peripheral nervous system a flapping tremor of the hands and the inability to draw a five-pointed star

(3) Cardiovascular system high output circulatory state

(4) Respiratory system hyperventilation and cyanosis secondary to hypoxia caused by increased shunting

(5) Renal oedema and kidney failure

(6) Hepatic spider neri, ascites and gynaecomastia

anaesthetic. In these patients, the anaesthetist should assess liver function, as described below, and should be aware of the precautions necessary to avoid infecting operating room personnel. These include: assuming that all patients possibly at risk are antigen positive until proven otherwise, wearing protective clothing (gloves, gown, mask, glasses), keeping needle sticks to a minimum, and using disposable anaesthetic equipment. Although virus $B$ is able to survive for days on surfaces such as table tops, it is sensitive to heat $\left(60^{\circ} \mathrm{C} \times 12\right.$ hours), ethylene oxide, bleach solutions and glutaraldehyde.

If contamination occurs from an antigen-positive patient, either by needle stick, abrasion (e.g., on the patient's teeth), or by material splashed into the eye or mouth, consideration must be given to the administration of immunoglobulin with a high content of antibody to hepatitis B surface antigen (anti-HBs) as soon as possible ${ }^{9}$ and preferably within seven days after exposure, in an initial dose of $5 \mathrm{ml}$ ( $500 \mathrm{mg}$ total immunoglobulin) i.m., and repeated one month later. In addition, liver function tests and screening for $\mathrm{HBs} \mathrm{Ag}$ and antibody should be carried out. If individuals are already antigen positive (unlikely) or have antibodies, then they are not at risk of further infection and the second injection should not be given. However, administration of anti-HBs should not be delayed pending such testing. It should be noted that anti-HBs is not 100 per cent effective and may merely delay the onset of hepatitis. In addition, although anti-HBs is a human antiserum, it may be responsible for allergic reactions. On the other hand, normal immunoglobulin with a low titre of anti-HBs is highly effective in preventing the development of hepatitis $\mathrm{A}$ if given sufficiently early in the incubation period. Normal immunoglobulin is not effective in the prevention of hepatitis B

Hepatitis B infection is a hazard for health-care workers and it is well recognised that there is an increased rate of infection in such specialties as: surgery, pathology, paediatrics, internal medicine, anaesthesia, obstetrics and gynaecology, and family practice. The advent of a hepatitis $B$ vaccine (Heptavax-B $^{(\mathbf{R})}$; Merck, Sharp \& Dohme) will hopefully reduce this hazard. At present, the vaccine is about 90 per cent effective and has undergone clinical trials in high risk groups.

\section{Preoperative assessment}

Preoperative assessment to identify the patient with liver disease is important but often neglected. ${ }^{10}$ Such assessment may be divided into three stages: examination of the patient, liver function tests, and quantification of hepatic reserve.

The patient should be questioned specifically as to current drug therapy, alcohol and drug abuse, previous jaundice or hepatitis, blood transfusions and previous anaesthetics (local, regional and general). In certain patients, consideration should also be given to enquiry about country of origin and sexual habits, because of the risk of viral B hepatitis.

Physical examination of the patient with liver disease involves assessment of all the body systems. However, from the anaesthetist's point of view, the important factors are: (1) is the patient well or unwell? and (2) what surgical procedure is contemplated? The liver's capacity to withstand insult is large and there must be considerable derangement of function before this is evident on clinical examination (Table III).

However, the patient may feel unwell long before their hepatic dysfunction can be quantified in adverse changes in liver function tests (Table IV). Similarly, because the tests are relatively nonspecific, abnormal values (particularly on one screening) may have little significance if the patient feels well. Although these observations are unscientific, clinical experience suggests that they are of value. This is particularly so when combined with the knowledge of the proposed operation, since there seems to be a relationship between the extent of the surgical procedure and patient out- 
TABLE IV Liver function tests

\begin{tabular}{|c|c|c|}
\hline Test & Normal value & Comment \\
\hline Albumin & $35-50 \mathrm{~g} / 1$ & $\begin{array}{l}\text { Lowered in chronic liver disease; } \\
\text { less than } 25 \mathrm{~g} / \mathrm{l} \text { indicates } \\
\text { scrious problem }\end{array}$ \\
\hline Alpha-1-fetoprotein & $2-10 \mu g / 1$ & Rajsed in hepatoma \\
\hline Bilirubin - total & $3-20 \mu \mathrm{mol} / \mathrm{l}$ & $\begin{array}{l}\text { Above } 20 \text { मmol/li clinical } \\
\text { jaundice }\end{array}$ \\
\hline Ceruloplasmin & $150-600 \mathrm{mg} / 1$ & Low in Wilson's disease \\
\hline Cholinesterase & $7-19 \mathrm{kU} / \mathrm{l}$ & Low in chronic liver discase \\
\hline \multicolumn{3}{|l|}{ Enzymes } \\
\hline Aminotransferases (AST, SGOT, SGFT) & $0-40 \mathrm{IU} / 1$ & $\begin{array}{l}\text { Raised in liver disease, but also } \\
\text { after myocardial infaret and } \\
\text { surgery }\end{array}$ \\
\hline Alkaline phosphatase (ALP) & $30-115 \mathrm{IU} / 1$ & Raised in biliary obstruction \\
\hline Lactate dehydrogenase (LDH) & $90-300 \mathrm{IU} /]$ & Raised in liver disease \\
\hline Hydroxybutyrate dehydrogenase (HBD) & $100-250 \mathrm{IU} / 1$ & $\begin{array}{l}\text { Isoenzyme of LDH; mare } \\
\text { specific for liver discase }\end{array}$ \\
\hline Gamma-glutamyl transpeptidase (GGT) & $\begin{array}{l}\text { 15-85 IU/1 } \\
\text { (Male) } \\
\text { 5-55 IU'l } \\
\text { (Female) }\end{array}$ & $\begin{array}{l}\text { Raised with chronic ingestion of } \\
\text { alcohol }\end{array}$ \\
\hline Globulin & $25-30 \mathrm{~g} / \mathrm{l}$ & Raised in chronic liver disease \\
\hline Glucose & $3.6-6 \mathrm{mumoll}$ & $\begin{array}{l}\text { Hypoglycaemia may occur in } \\
\text { liver discasc }\end{array}$ \\
\hline Prothrombin time & $11-13$ secs & $\begin{array}{l}\text { Prolonged in biliary obstruction } \\
\text { and hepatocellular disease }\end{array}$ \\
\hline
\end{tabular}

come. Other relevant investigations which should be considered in determining diagnosis and hepatic reserve are shown in Table $\mathrm{V}$.

The third stage of assessment of the patient with liver disease involves determination of hepatic reserve. Child ${ }^{11}$ described a classification system including two laboratory tests and three clinical observations (Table VI). It should be noted that this classification refers specifically to portacaval anastamosis, i.e., major surgery, and therefore may not be entirely relevant for more minor procedures. In addition, assessment of ascites, neurological disorder, and nutrition is somcwhat imprecise. More recentiy, Pugh ${ }^{12}$ has modified Child's scoring system to include only one clinical observation (Table VII). In general, patients with chronic liver disease, who are classified as Child Grade $A$ or equivalent, are described as having compensated liver disease and do not constitute a major anaesthetic risk, whatever the surgical procedure contemplated. By contrast, if patients are graded $B$ or $C$ (decompensated liver disease), they will always be a major anaesthetic risk, but the outcome will be determined in addition by the extent of the surgical procedure. This is in contradistinction to using the ASA Physical Status classification which does not take into account the weight of the patient (i.e., nutritional status) or surgical procedure and was not intended to be used prospectively. ${ }^{13}$

\section{Anaesthetic considerations}

With the exception of halothane (as will be discussed), there is no clear evidence that any of the

TABLE V Relevant investigation for assessment of liver function

Haemoglobin and haematocrit

Serum electrolytes creatinine

Arterial blood gases

Electrocardiogram

Chest $x$-ray

Ultrasound

CT scan

Liver scan

Oral or intravenous cholangiogram

Percutaneous transhepatic cholangiogram

Endoscopic radiological retrograde cholangiopanereatography Angiography

Needle liver biopsy 
TABLE VI Patient status/hepatic reserve (Child's)

\begin{tabular}{llll}
\hline & Class $A$ & Class $B$ & Class $C$ \\
\hline Serum bilinubin $\left(\mu \mathrm{mol}^{-1}\right)$ & 40 & $40-50$ & 50 \\
Scrum albumin $\left(\mathrm{g}^{-1}\right)$ & 35 & $30-35$ & 30 \\
Ascites & None & Easily controlled & Poorly controlled \\
Neurological disorder & None & Minimal & Advanced coma \\
Nutrition & Excellent & Good & Poorwith wasting \\
Risk of operation & Good & Moderate & Poor \\
\hline
\end{tabular}

TABLE VII Patient status/hepatic reserve (Pugh's)

\begin{tabular}{|c|c|c|c|}
\hline & \multicolumn{3}{|c|}{$\begin{array}{l}\text { Points scored for increasing } \\
\text { abnormalies }\end{array}$} \\
\hline & $I$ & 2 & 3 \\
\hline Serum bilirubin ( $\mu$ mol $1^{-1}$ ) & 25 & $25-40$ & 40 \\
\hline Serum albumin $\left(\mathrm{g} \mathrm{l}^{-1}\right)$ & 35 & $28-35$ & 28 \\
\hline $\begin{array}{l}\text { Prothrombin time (secs) } \\
\text { (increase over control) }\end{array}$ & $1-4$ & $4-6$ & 6 \\
\hline Encephalopathy (grade) & None & $1 \& 2$ & $3 \& 4$ \\
\hline Risk of operation & Good & Moderate & Poor \\
\hline
\end{tabular}

5-6 points: good operative risk (equivalent to Child Grade A).

7-9 points: moderate operative risk (equivalent to Child Grade B).

10-15 points: poor operative risk (equivalent to Child Grade C)

currently used anaesthetic agents and techniques have any definite advantage or recognisable detrimental effect in patients with normal liver function preoperatively. However, there are certain steps which should be taken by the anaesthetist when dealing with specific types of liver disease.

\section{Chronic liver disease}

Most commonly, patients with chronic liver disease will present for surgery unrelated to their liver dysfunction. Cirrhosis is the pathological finding in this condition and is most commonly related to alcohol abuse, immunological disease, or viral hepatitis. The hepatic reserve of such patients should be assessed as already described.

A consequence of cirthosis is obstruction to liver blood flow leading to portal hypertension. The resultant back pressure opens up anastomoses between the portal and systemic circulations; normally these do not cause problems, but when oesophageal varices occur, acute life-threatening haenorrhage may result. This is often a dramatic medical presentation, engendering much surgical enthusiasm, but it should be realised that variceal haemorrhage is often a terminal event since liver damage may be so extensive as to be incompatible with life, even if the variceal haemorrhage can be controlled. Nevertheless, numerous surgical procedures have been evolved to reduce portal hypertension (e.g., porta-caval shunt) or obliterate oesophageal varices by direct attack. ${ }^{14}$ It should be realised that porta-systemic shunting is a major surgical endeavour with a not inconsiderable mortality. Furthermore, it has yet to be shown that this type of procedure significantly prolongs the patient's life, although immediate control of variceal haemorrhage may be achieved, by accepting a high initial mortality. More conventional control of variceal haemorrhage may be effected by the Sengstaken-Blakemore tube or by injection of oesophageal varices which will control haemorrhage in the majority of patients. Recently, results of trials of oesophageal injection suggest that

TABLE VIII Anaesthesia for the patient with liver disease

\begin{tabular}{|c|c|}
\hline \multicolumn{2}{|c|}{ Surgical procedures* relazed to liver disease } \\
\hline Pre-op & $\begin{array}{l}\text { Check HBs Ag status; vitamin K; rchydration; } \\
\text { mannitol if necessary }\end{array}$ \\
\hline Pre-med & Oral diazepam; avoid narcotics \\
\hline Induction & $\begin{array}{l}\text { Thiopentone; succinylcholine for emergency } \\
\text { intubation; pancuronium for non-urgent use } \\
\text { and maintenance of } n, m \text {, blockade }\end{array}$ \\
\hline Maintenance & $\begin{array}{c}\mathrm{O}_{2}: \mathrm{N}_{2} \mathrm{O} \text {, IPPV to normocapnia; increments of } \\
\text { narcotic - fentanyl; isoflurane, enflurane, } \\
\text { or halothane permitted but control dosage }\end{array}$ \\
\hline Monitoring & $\begin{array}{l}\text { Pulse, ECG, BP, CVP; urine, fluid balance } \\
\text { chant }\end{array}$ \\
\hline$p$ & $\mathrm{O}_{2}$ therapy; mannitol if necessary \\
\hline
\end{tabular}

*These procedures include: injection of oesophageal varices, porta-systemic shunts, oesophageal transection, LeVeen shunt, and laparotomy for biliary obstruction.

N.B. Regional anaesthesia is not very suitable; there may be clotting abnormalities and inability to metabolise the local anaesthetics used. 
patients' lives can be prolonged as compared with a control group. However, the medical literature is strewn with optimistic forecasts of various forms of treatment of oesophageal haemorrhage in the cirthotic patient and the reader is urged to be cautious in uncritical acceptance. Many of the procedures outlined above involve general anaesthesia and often a laparotomy. But it should be clear that unless the patients are Child Grade A, they are severe anaesthetic and surgical risks.

Table VIII outlines anaesthetic techniques which are suitable for surgical procedures related to liver disease. In addition, there are many diagnostic procedures which may require the presence of an anaesthetist. These include: gastroscopy, liver biopsy (either percutaneously or at the time of laparoscopy), liver scan, angiography, percutaneous transhepatic cholangiography, endoscopic radiological retrograde cholangiopancreatography, and laparoscopy. These procedures usually do not require general anaesthesia and arc commonly carried out using sedation with intravenous diazepam. However, this may not be satisfactory for children and a general anaesthetic may be required. Such patients should be assessed as if they were having a major procedure, in order to avoid problems. Diazepam is a highly protein-bound drug and, if used in moderate doses, does not normally cause unexpected cardiorespiratory depression or unconsciousness in patienrs with compensated liver disease. However, diazepam has many of the properties of a general anaesthetic agent and therefore, on occasion, patients may require resucitative measures after what appears to have been a reasonable dose. Thus, facilities for cardiorespiratory support should be available in diagnostic areas when patients with liver disease are being investigated.

Injection sclerotherapy is currently in vogue again in the management of oesophageal varices. ${ }^{14}$ Sclerotherapy is carried out using either a fibreoptic or rigid gastroscope, with the patient sedated with intravenous diazepam. General anaesthesia may be required, however, in centres where rigid gastroscopy is the preferred method.

At the time of surgery and general anaesthesia, the anaesthetist should pay particular attention to (1) avoiding premedicant drugs in patients in Child Grades $B$ and $C$; (2) titrating the intravenous induction agent as there is great variation in the dose required as a result of changes in drug distribution;
(3) maintaining a normal arterial $\mathrm{pCO}_{2}$ to minimise changes in liver blood flow; (4) limiting the dose of intravenous narcotics, in proportion to the degree of liver disease present; (5) monitoring neuromuscular blockade to minimise the dose of relaxants used; and (6) minimising the dose of volatile agents so as not to adversely affect liver blood flow - halothane may be safely used in such patients provided there is no history of a recent previous halothane anaesthetic or any history of an adverse reaction after halothane anaesthesia, however previous or distant.

\section{Biliary obstruction}

Jaundice is a clinical finding characterised by yellow pigmentation, first seen in the sclerae, and then in the mucous membranes (palate), skin and other tissues when serum bilirubin exceeds $20 \mu$ moles litre ${ }^{-1}$. The causes of jaundice according to mechanism are: increased bile pigment production, defective uptake and transport within the hepatocyte, defective conjugation, or defective excretion. In practice, there may be difficulty in attributing jaundice specifically to one of these mechanisms since any of them may be involved.

A prolonged prothrombin time is commonly found in the patient with biliary obstruction and is due to inability to absorb vitamin $K$ from the gut as bile salts are absent. Several other clotting factors also require the presence of vitamin $\mathrm{K}$ and therefore complex blood coagulation problems may occur. If there is hepatocellular diseasc, defective synthesis may also lead to a lack of clotting factors and is associated with a low senum albumin concentration. All jaundiced patients should receive parenteral vitamin $\mathbf{K}$ preoperatively, and if prothrombin activity does not return to normal, fresh frozen plasma should be available at the time of diagnostic or surgical procedures to reduce the risk of haemorrhage. ${ }^{15}$

In patients where the bilirubin is in excess of 140 $\mu$ moles litre ${ }^{-1}$, there is an increased risk of postoperative renal failure and sepsis; this is most likely due to portal and systemic endotoxaemia and renal intravascular coagulation. It has been shown that adequate preoperative rehydration, antibiotic therapy and the maintenance of a diuresis pre-, per- and postoperatively will reduce the incidence of such renal failure. ${ }^{16}$

The severely jaundiced patient coming for surgery has biliary obstruction. Most of these patients do not have primary liver cell damage and preopera- 
tive testing should have established hepatic reserve (including HBs Ag status) and the site of obstruction (by ultrasound andior endoscopic retrograde cholangiopancreatography), most often due either to stones or cancer. Laparotomy for "undiagnosed jaundice" is to be discouraged as the patient either has an inoperable lesion, or of more immediate concem, viral hepatitis which may lead to severe deterioration of liver function postoperatively. ${ }^{8}$

Table VIII summarises the anaesthetic approach to these patients. Particular attention should be paid to: (1) checking the prothrombin time; (2) ensuring that the patient is adequately hydrated preoperatively; (3) inducing a diuresis (of at least $50 \mathrm{ml} /$ hour) pre-, per- and postoperatively, by fluid loading and the use of either mannitol or furosemide (with CVP monitoring if necessary), if the bilirubin is greater than $140 \mu$ moles litre ${ }^{-1}$; (4) monitoring the urine output by indwelling catheter during anaesthesia of all jaundiced patients; (5) realising that there is no contraindication to the use of halothane in these patients provided that the cause of their jaundice is known and does not relate to a previous halothane anaesthetic.

\section{Liver trauma and tumours}

Liver trauma occurs most commonly as a result of either: motor vehicle accidents or knife or gunshot wounds. Tumours of the liver may be either primisy (hepatoma) or may result from secondary spread from cancer elsewhere in the body. Surgical procedures in the management of such patients range from simple suture of liver lacerations to partial hepatectomy and even liver transplantation.

Any of these surgical procedures is fraught with hazard for the patient and should be considered as high risk. Problems include major haemorrhage, air embolus due to opening the inferior vena cava, acid base problems, difficulties in controlling the patient's temperature as a result of blood loss and the need for massive blood transfusion, and major changes in haemodynamics as a result of interference with venous return to the heart.

The anaesthetic aspects of these difficult cases are well reviewed in the recommendations for further reading.

\section{Postoperative liver dysfunction}

Following anaesthesia and surgery, liver dysfunction is usually first manifested by the appearance of jaundice. A rise in bilirubin alone is fairly common after major surgery. The usual causes are: (1) blood transfusion, (2) tissue injury, and (3) infection. In addition, pre-existing liver disease may deteriorate as a result of these factors.

Elevated serum enzymes (transaminases) also occur commonly after major surgery and are probably due to the tissue damage involved in the surgical procedure. Recently, attention has been drawn to the role of hypoxia in postoperative liver dysfunction. ${ }^{77}$ It has been suggested that many of these minor changes may be due to hepatic hypoxia occurring either during anaesthesia or in the immediate postoperative period. However, the majority of these patients feel well and will recover without any permanent effects on their liver

Very rarely, straightforward anaesthesia and surgery (not accompanied by any obvious hypoxia, hypotension, or acid-base disturbance) is followed by the development of severe liver dysfunction, manifest as both a rise in bilirubin and adverse changes in other liver function tests such as enzymes and prothrombin time. ${ }^{18}$ Most importantly, the patient feels and looks unwell. These patients have postoperative hepatitis, a severe complication, which occasionally may lead to death as a result of fulminant hepatic failure. In these patients it is often impossible to establish the cause of their liver failure and suspicion falls on the anaesthetic drugs used. Many of such patients have received halothane and furthermore, the majority have had two halothane anaesthetics relatively close together. It should be made clear that, before diagnosing the condition as halothane associated hepatitis, all other causes of hepatitis, such as viral hepatitis, infection, known hepatoxic drugs, preexisting liver disease, and liver injury during surgery should be excluded. It should also be remembered that liver dysfunction has been associated with all types of anaesthesia, including local and regional anaesthesia.

The mechanism whereby halothane may cause liver damage in man is not clear. In rats, it is possible to produce liver damage under some circumstances with halothane when the inspired oxygen is grossly reduced and the metabolizing capacity of the liver is increased (enzyme induction). ${ }^{19}$ However, the fact that this can be done in experimental animals does not necessarily mean that the same mechanism applies in man. In the rat it is likely that a metabolic product of reductive metabolism of halothane is responsible for the 
damage and it has been suggested that man also produces such metabolic breakdown products of halothane which then damage the liver ${ }^{20}$ An alternative explanation, since most patients with halothane associated hepatitis have had more than one exposure to the agent, is that an immune response is involved, which may or may not be combined with metabolism of halothane. ${ }^{21,22}$

The anaesthetist should be aware of several points, with regard to the use of halothane and prevention of the occurrence of halothane associated hepatitis. Firstly, halothane should not be administered to a patient who has received the drug in the recent past; most authorities - on emotional rather than scientific grounds - feel that an interval of several months is probably satisfactory; but, there is probably no ethical means of accurately determining this interval. Secondly, halothane should never be administered to a patient who, after a previous halothane anaesthetic, has had any evidence of liver dysfunction which could not be explained. The incidence of halothane-associated hepatitis is usually stated to be of the order of 1 in 10,000 anaesthetics or, put another way, the average anaesthetist is only likely to encounter such a case once in a working life-time. It is of interest that the figure of 1 in 10,000 is also quoted in a recent study of mortality in anaesthesia for the risk of death totally as a result of anaesthesia (excluding hepatic failure $)^{23}$ and furthermore, a similar figure is quoted for the incidence of serious neurological sequelae after epidural anaesthetics. ${ }^{24}$

Halothane associated hepatitis appears to occur more commonly in obese, middle-aged women; but in contrast to experimental animals, there appears to be no relationship to the length of the anaesthetic, enzyme induction, hypoxia, or nutritional state in humans. ${ }^{18}$ Halothane-associated hepatitis is a very rare event in children ${ }^{25}$ and probably they can be safely given halothane repeatedly without too much fear of the development of postoperative hepatitis. Enflurane, like all other anaesthetics, has been associated on rare occasions with liver damage. However, it is not felt that an entity of "enflurane hepatitis" exists and many people use enflurane as the second agent when trying to avoid repeated halothane anaesthesia. Isoflurane has not been sufficiently used to date to be certain that it does not cause hepatitis, but on theoretical grounds, it should be safe as it undergoes very little metabolism in man and its cardiovascular effects are minimal when low concentrations are used.

Any patient who develops postoperative liver dysfunction which cannot be explained and which might have been related to the anaesthetic, whatever the agents used, should be told and every effort should be made to not give these drugs subsequently if another anaesthestic is required. If the cause can be established, as not due to the anaesthetic, this should be clearly stated in the patient record so as to avoid confusion in the future.

\section{References}

1 Strumin $L$. The splanchnic, hepatic and portal circulations. In The Circulation and Anaesthesia: Applied Physialogy and Pharmacology. (Ed) PrysRoberts C. Oxford, London, Edinburgh, Melbourne: Blackwell Scientific Publications, 1980.

2 Andreen $M$. Inhalation versus intravenous anaesthesia. Effects on the hepatic and splanchnic circulation. Acta Anaesth Scand Suppl 1982; 75; 25-31.

3 Abdel Salam AR, Drummond GB, Bauld HW, Scott $D B$. Clearance of indocyanine green as an index of liver function during cyclopropane anaesthesia and induced hypotension. Br J Anaesth 1976; 48: 231-8.

4 Gelman SI. Disturbances in hepatic blood flow during anesthesia and surgery. Arch Surg 1976; 111: 881-3.

5 Bieybuyck $J F$. Anesthesia and hepatic metabolism: current concepts of carbohydrate hemostasis. Anesthesiology 1973; 39: 188-98.

6 Cohen $R D$, Simpson BR. Lactate metabolism. Anesthesiology 1975; 43: 661-73.

7 Jones PM. Blood donors with a history of jaundice. Brit Med J 1982; 285: 834.

8 Powell-Jackson $P$, Greenway $B$, Williams $R$. Adverse effects of exploratory laparotomy in patients with suspected liver disease. Br J Surg 1982; 68: 449-51.

9 Use of immunoglobulin with high content of antibody to hepatitis B surface antigen (anti-HBs).

Working party on the clinical use of specific immunoglobulin in hepatitis B. Brit Mcd J 1982; 285 : 95I-4.

10 Strunin L. Preoperative assessment of the patient with liver dysfunction. Br J Anaesth 1978; 50 : 25-31.

11 Child CG. The liver and portal hypertension. In 
Major Problems In Clinical Surgery. Vol. I. (Ed) Child CG. Philadelphia, London and Toronto: W/B Saunders, 1966.

12 Fugh RNH, Murray-Lyon IM, Dawson JL, Pietroni $M C$, Williams $R$. Transection of the oesophagus for bleeding varices. Brit J Surg 1973; 60; 646-9.

13 Saklad $M$. Grading of patients for surgical procidures. Anesthesiology 1941; 2: 281-4.

14 Clark $A W$, Westaby $D$, Silk DBA, Dawson $J L$, MacDougall BRD, Mitchell KJ. Strunin L. Williams $R$. Prospective controlled trial of injection sclerotherapy in patients with cirrhosis and recent variceal haemorrhage. Lancet 1980; 2: 552-4.

15 Gazzard BG, Lewis ML, Ash G, Rizza CR. Bidwell $E$, Williams $R$. Coagulation factor concentrate in the treatment of the haemorthagic diathesis of fulminant hepatic failure. Gut 1974; 15: 993-8.

16 Hatfield ARW, Terblanche J, Fataar S, Kernoff $L$, Tobias $R$, Girdwood AH, Harries-Jones $R$, Mlarkx IN. Preoperative cxtcmal biliary drainage in obstructive jaundice. A prospective controlled trial. Lancet 1982; 2: 896-9.

17 Pohl $L R$, Gillette $J R$. A perspective on halothaneirduced hepatotoxicity. Anesth Analg 1982;61 809-11.

18 Walton B. Simpson BR, Strunin L, Doniach D. Perrin J, Appleyard AJ. Uncxplained hepatitis following halothane. Br Med J 1976; 1: 1171-6.

19 McLain GE, Sipes IG, Brown BR. An animal model of halothane hepatotoxicity. Roles of enzyme induction and hypuxia. Anesthesiology 1979; 51: 321-6.

20 Cousins MJ, Sharp JH, Gourlay GK, Adams $J F$, Haynes WD, Whitehead $R$. Hepatotoxicity and halothane metabolism in an animal model with ajplication for human toxicity. Anaesth Intensive Care 1979; 7: 9-24.

21 Vergani $D$, Mieli-Vergani $G$, Alberti A, Neuberger J, Eddlestone ALWF, Davis $M$, Williams $R$. Antibodies to the surface of halothane altered rabbit hepatocytes in patients with severe halothaneassociated hepatitis. N Engl J Med 1980; 303: $65-71$.

22 Neuberger J, Vergani GM, Tredger JM, Davis $M$, Williams $R$. Oxidative metabolism of halothane in the production of altered hepatocyte membrane antigens in acute halothane-induced necrosis. Gut 1982; 22: 669-72.

23 Lunn JN, Mushin WW. Mortality associated with anaesthesia. London: Nuffield Provincial Hospitals Trust, 1982.
24 James FM. The Anesthesiology Triad in Obstetrics. Reports of Scientific Meetings. Anesthesiology 1982; 56: 335-6.

25 Lewis RB, Blair $M$. Halothane hepatitis in a young child. Br J Anaesth 1982; 54: 349-54.

26 Inactivated Hepatitis B Virus Vaccine. Morbidity And Mortality Weekly Report. HHS Publication No. (CDC) 82-8017. Centers For Disease Control. Atlanta, Georgia. 1982; 31: 317-9.

\section{Further Reading}

1 Strunin L. The Liver and Anaesthesia. Major Problems in Anaesthesia Vol 3. London, Philadelphia, Toronto: WB Saunders Ltd, 1977.

2 Brown BR. Anesthesia and the Patient with Livcr Disease. Philadelphia: FA Davis Company, 1981.

3 Sheriock S. Disease of the Liver and Biliary System. 6th Edition. St. Lovis, Toronto, London: CV Mosby, 1981.

4 Wright R, Alberti KGMM, Korran S, MillwardSadler GH. Liver and Biliary Disease. Philadelphia: WB Saunders Company Ltd, 1979. 